\title{
Non Invasive Ventilation in Acute Hypercapnic Respiratory Failure
}

\author{
Mark W. Elliott, MA, MB, BChir, MD, FERS
}

Department of Respiratory Medicine, Sleep and Non-invasive Ventilation Service, St James's University Hospital, Leeds, United Kingdom

\section{ABSTRACT}

This article reviews the use of non invasive ventilation (NIV) in the management of acute hypercapnic respiratory failure (AHRF). Most of the evidence and experience comes from treating acute exacerbations of chronic obstructive pulmonary disease (AECOPD) but this has been extrapolated to other conditions. Patient selection, contraindications, how to monitor and recognise when NIV is failing and what the options are then, are discussed. There are differences in criteria for initiation of NIV and the way that it is applied in patients with neuromuscular disease, chest wall disorders and obesity. The importance of staff experience and training as well as the need for regular audit are stressed. Finally, there is some horizon scanning about what may be next in the management of AHRF. (BRN Rev. 2017;3:299-312) Corresponding author: Mark W. Elliott, mark.elliott2@nhs.net

Key words: COPD. Hypercapnia. Neuromuscular disorders. Non invasive ventilation. Obesity. Respiratory failure. 


\section{INTRODUCTION}

Over the last 30 years non invasive ventilation (NIV) has become well established as a tool in the management of patients with acute life threatening respiratory illness. This article will focus on the use of NIV in acute (usually acute on chronic) hypercapnic respiratory failure (AHRF). NIV is now considered part of routine care for patients with respiratory failure due to acute exacerbation of chronic obstructive pulmonary disease (AECOPD) ${ }^{1}$.

An AECOPD is a common reason for admission to hospital and it is in this condition that there is the best evidence for the effectiveness ${ }^{2}$, and cost effectiveness of NIV in $\mathrm{AHRF}^{3,4}$. Largely because of the experience in AECOPD, and because clinical trials have not been performed in other disease areas, data from studies in AECOPD are extrapolated to other conditions presenting with AHRF. Although NIV is usually considered to be a relatively new innovation in the management of AHRF, there are a number of studies involving significant numbers of patients from France published in the 1960s (summarised in reference ${ }^{5}$ ).

\section{PATHOPHYSIOLOGY OF RESPIRATORY FAILURE IN AECOPD}

Acute respiratory failure develops when the respiratory muscles fail to achieve adequate alveolar ventilation despite high levels of diaphragmatic activity, i.e., when the respiratory muscle pump does not have sufficient capacity to deal with the load of the respiratory system. This occurs for a number of reasons, leading to the development of vicious cycles which interact with each other.
Worsening airflow obstruction and/or secretion retention increase the load against which the respiratory muscle pump must function. Respiratory muscle capacity may already be reduced due to malnutrition or oral corticosteroids and also to mechanical disadvantage of the inspiratory muscles due to hyperinflation ${ }^{6}$. When faced with a load that exceeds the capacity of the respiratory muscle pump, a rapid shallow breathing pattern develops. This is beneficial in reducing respiratory muscle energy expenditure, but occurs at the expense of alveolar ventilation ${ }^{7}$. It may also worsen hyperinflation, further reducing respiratory muscle capacity because of increased mechanical disadvantage of the inspiratory muscles. The level of intrinsic positive airway pressure (PEEPi) may also rise; the first part of each breath is spent decompressing gas rather than in achieving ventilation. This is described as an inspiratory threshold load and can be offset by continuous positive airway pressure (CPAP) alone ${ }^{8}$. Respiratory failure may also ensue if central drive is reduced for example due to injudicious sedative or if carbon dioxide rises sufficient to cause to cause coma. As a consequence of these factors, the level of arterial carbon dioxide $\left(\mathrm{CO}_{2}\right)$ rises and respiratory acidosis ensues. This in turn compromises respiratory muscle function further.

Non invasive ventilation is usually provided with a bilevel ventilator and has a number of potential beneficial effects. Inspiratory positive airway pressure (IPAP) supports the respiratory muscles as they struggle to deal with the excessive load. Respiratory rate falls, tidal volume increases and blood gases improve. This is then beneficial in terms of muscle function. The fall in respiratory rate also allows more time for alveolar emptying, reducing hyperinflation, improving inspiratory muscle mechanical 
function and for reducing PEEPi. Both of these factors now increase respiratory muscle capacity, with further benefit, and vicious cycles become virtuous cycles. The inspiratory threshold load can also be counterbalanced by extrinsic PEEP (also known as expiratory positive airway pressure (EPAP)). This has the additional effect of improving patient ventilator synchrony. Other modes of NIV are available; they have either not been shown to be superior to standard bilevel ventilation in the acute situation or only been evaluated in chronic domiciliary NIV. Standard bilevel ventilation remains the gold standard in AHRF.

\section{EVIDENCE BASE FOR NIV IN AECOPD}

The earliest studies in the modern era in AECOPD were generally ${ }^{9,10}$, but not exclusively ${ }^{11,12}$, performed in the Intensive Care Unit (ICU) and showed a significant reduction in the need for endotracheal intubation, in-hospital mortality, length of stay and complications with NIV. Complications were generally attributable to intubation and infectious in nature and, while most commonly affecting the respiratory tract, other organ systems, e.g. the urinary tract, were affected ${ }^{13,14}$. This is probably consequent upon the need for invasive monitoring when patients are intubated and ventilated. Complications increase morbidity and mortality, prolong ICU and hospital stay, and increase costs. The major benefits of NIV are therefore achieved by avoiding the need for endotracheal intubation (ETI). Although many patients find NIV a relatively unpleasant experience, dyspnoea, the predominant presenting symptom of an AECOPD, is relieved more rapidly ${ }^{12}$. Non invasive ventilation should be considered as providing respiratory support at a level intermediate between conventional oxygen therapy and ETI and mechanical ventilation (MV); it replaces neither, but is complementary and part of a continuum.

Non invasive ventilation can be delivered safely and with benefit outside the ICU. The Yorkshire Non Invasive Ventilation (YONIV) study $^{15}$, a multicentre study in the United Kingdom (UK), enrolling 236 patients, was performed on general wards and showed that, compared to standard treatment, treatment failure (defined by a priori agreed criteria indicating need for ETI and MV) was reduced ( $15 \%$ versus $27 \%, \mathrm{p}=0.02)$ as was in-hospital mortality $(10 \%$ versus $20 \%, \mathrm{p}=0.05)$. NIV led to a more rapid improvement in $\mathrm{pH}$ and greater fall in respiratory rate. However, in a post-hoc analysis the sub group with a $\mathrm{pH}<7.30$ had an unacceptably high failure rate and mortality. As experience and confidence increase, more patients can be managed outside the ICU $^{16}$. It is very important to note that the model of care varies from country to country and ICU means different things, particularly in terms of staffing levels, and it is best to consider the needs of the patient and how and where they can be best met rather than specifying ICU, general ward, etc. Current guidelines recommend that NIV be delivered in a specialised unit with a nurse to patient ratio of 1 to 2, at least in the first 24 hours when the need for nursing supervision and input is greatest. It is important that there is sufficient throughput of patients through the unit for staff to use and improve their skills ${ }^{17}$.

The experience of staff is key to successful delivery of NIV. There is anecdotal evidence that success rates on an ICU that is inexperienced in NIV are worse than on a general ward 
on which the staff have had a lot of experience of NIV. On an ICU, it is easier to default to that with which staff are more familiar and comfortable, an intubated, sedated patient, at the first sign of any difficulty with NIV. Outside the ICU, staff must identify and solve problems first and only when that fails resort to ETI and MV. It is important to note that the results achieved in a clinical trial, in which there is usually greater attention to detail, quality assurance and sometimes more staffing available, may not be achieved in standard everyday clinical practice. Indeed a national audit ${ }^{18}$ performed by the British Thoracic Society (BTS) in the UK showed that one third of the patients for whom there is the best evidence base for NIV in AECOPD did not receive it. This turned out to be fortuitous as the patients who did receive NIV had a worse outcome than those treated conventionally. This suggests that there was an educational gap both in understanding when (doctors) and how (doctors, nurses and therapists) NIV should be delivered to a patient. The authors concluded that "the audit raises concerns that challenge the respiratory community to lead appropriate clinical improvements across the acute sector". Subsequent audits have shown a substantial improvement, but emphasise the importance of auditing performance against a benchmark and implementing change if standards are not being met. This should be a continuous process, as staff turnover is inevitable, with units having a programme of education for new starters and regular refreshers for established staff.

\section{WHEN TO START NIV}

The main focus of initial treatment in a patient with an AECOPD should be the institution of standard medical therapy, most importantly including oxygen targeted to a saturation of 88 to $92 \%$. In a randomised controlled trial (RCT), Austin et al. ${ }^{19}$ showed that there was a substantial survival advantage when oxygen was delivered to this target saturation range compared to high flow oxygen (8 to 10 litres/minute). Plant et al. ${ }^{17}$ showed that $20 \%$ of patients acidotic on arrival in hospital corrected their $\mathrm{pH}$ into the normal range with the above measures. Patients who remain acidotic ( $\mathrm{pH}<7.35)$ with tachypnoea (respiratory rate $>23$ breaths per minute) and hypercapnic $\left(\mathrm{PaCO}_{2}>45 \mathrm{mmHG}\right)$ after one hour should be started on $\mathrm{NIV}^{20}$. In the $\mathrm{pH}$ range 7.30 to $7.35,80 \%$ of patients will get better without NIV, though only 10 patients need to be treated with NIV to avoid one intubation ${ }^{15}$; if the patient is reluctant to use NIV, it is reasonable to repeat arterial blood gases after one hour, and, if the $\mathrm{pH}$ and respiratory rate are improving, to continue standard treatment. However, once the $\mathrm{pH}<7.30$, the prognosis is much worse ${ }^{9,17}$ : without NIV $50 \%$ of patients will meet criteria for $\mathrm{ETI}^{15}$ and patients need to be made aware that they are running significant risks without NIV.

The more severe the acidosis the greater the risk of NIV failure, but there is no lower $\mathrm{pH}$ value below which a trial, maybe short, of NIV is not appropriate (however see section on contraindications below). Two studies have compared NIV directly with invasive ventilation ${ }^{21,22}$. The mean pH was 7.20, significantly lower than in the studies discussed above. In the study of Conti et al. ${ }^{21}$ survival was similar in both groups, but in patients in whom NIV was successful advantages included shorter duration of ICU and hospital stay, fewer complications, reduced need for long term oxygen therapy and fewer hospital readmissions in the year following. The study of Jurjevic et al. ${ }^{22}$ enrolled patients similar to 


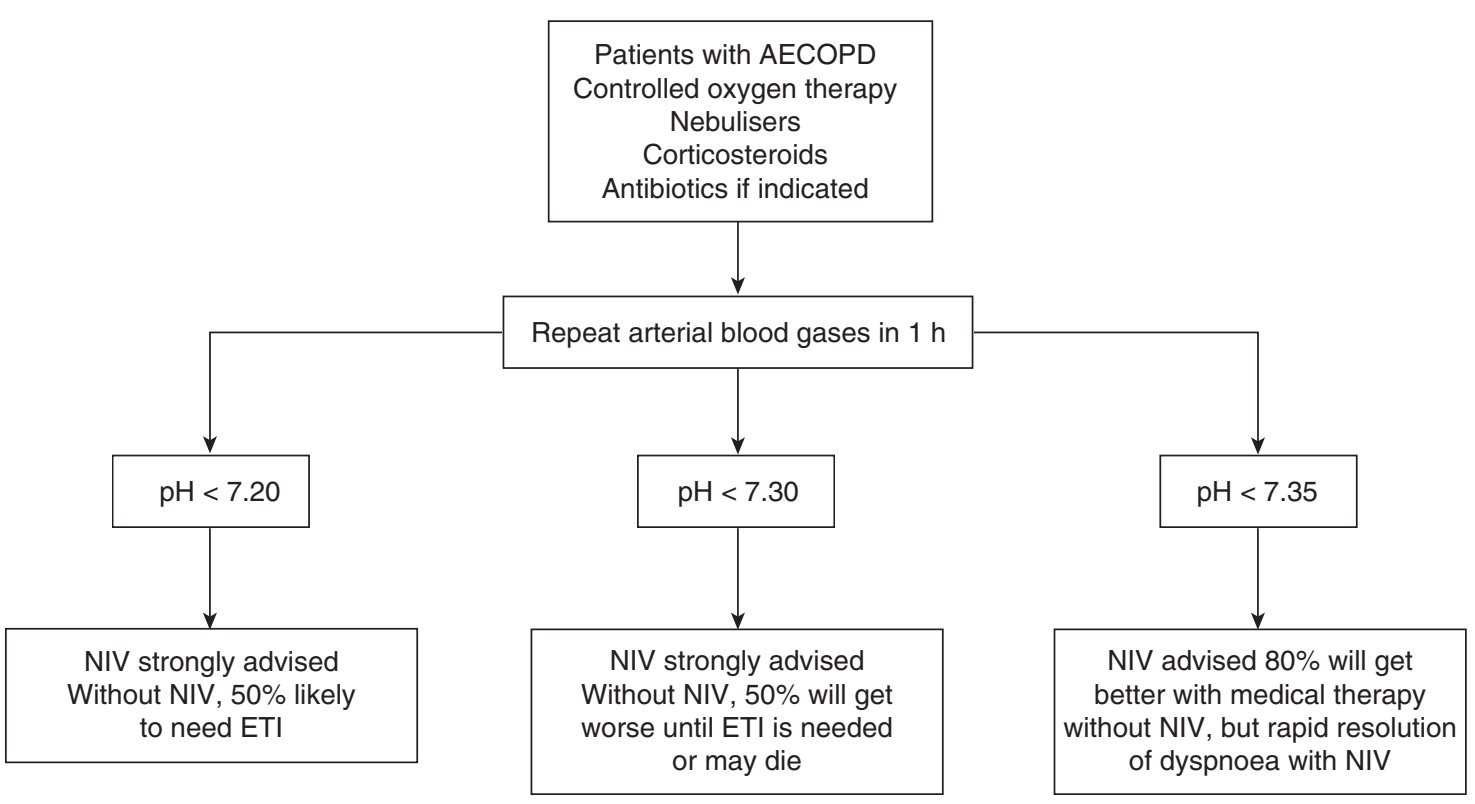

Figure 1. A schema for the management of a patient with ventilator respiratory failure due to an acute exacerbation of chronic obstructive pulmonary disease (COPD) (reproduced with permission from the CCERS 2013. Breathe Sep 2013, 9 (5) 338-348; DOI: 10.1183/20734735.043812).

AECOPD: acute exacerbation of chronic obstructive pulmonary disease; ETI: endotracheal intubation; NIV: non invasive ventilation.

those in the Conti study, but inclusion criteria and primary end points were not clearly defined. Mortality was similar in the two groups. Patients receiving bilevel NIV had fewer episodes of ventilator-associated pneumonia and less requirement for tracheostomy.

See figure 1 for a schema of the management of the patient with ventilatory failure due to an AECOPD.

In the BTS audit $11 \%$ of patients had a mixed metabolic/respiratory acidosis ${ }^{18}$. Although this was not investigated, further standard criteria, in particular the level of $\mathrm{PaCO}_{2}$, may not apply: the patient with a metabolic acidosis should have a low $\mathrm{pH}$ and therefore a normal $\mathrm{PaCO}_{2^{\prime}}$ because they cannot increase ventilation sufficiently to exhale $\mathrm{CO}_{2}$, may be high for them, and therefore NIV is reasonable even though the patient is not hypercapnic.

\section{CONTRAINDICATIONS}

There are very few absolute contraindications. These are mostly due to practical considerations of applying the mask, i.e. actively vomiting, facial deformity or trauma, uncontrolled agitation, etc. There are other situations requiring enhanced monitoring and special care, e.g. pneumothorax, haemodynamic instability ${ }^{20}$. Coma has been described as a contraindication to NIV, but in a large case series, 
Diaz et al. ${ }^{23}$ showed no difference in outcome between patients with and without hypercapnic coma. In patients who are comatose due to $\mathrm{CO} 2$ narcosis, NIV can still be applied with success in the study of Conti et al. ${ }^{21}$ the need for urgent intubation due to respiratory arrest, apnoeic episodes, psychomotor agitation requiring sedation, heart rate below 60 beats $/ \mathrm{min}$, and systolic arterial pressure below $80 \mathrm{mmHg}$, excluded patients from the study. The BTS/ Intensive Care Society (ICS) Guidelines ${ }^{20}$ recommend immediate intubation if in respiratory arrest or peri arrest unless there is rapid recovery from manual ventilation or provision of NIV, when it is impossible to fit a non-invasive interface or when the risk benefit analysis by an experienced clinician favours a better outcome with invasive ventilation than with NIV. However, all these recommendations are grade $\mathrm{D}$, i.e., expert opinion.

\section{STARTING NIV - TECHNICAL CONSIDERATIONS AND MONITORING (FIG. 2)}

Initially pressures should be set at relatively low levels (IPAP/EPAP) of $15 / 5$ to allow patients to get acclimatized, but need to be up-titrated by $2-5 \mathrm{~cm}$ steps every 10 minutes until a therapeutic response is achieved or the maximum that can be tolerated is reached. In patients with more severe acidosis, a higher starting IPAP should be used. Generally, a fullface mask should be used in the acute setting as many patients mouth breath when very breathless. Oxygen should be added if necessary, aiming for saturations of $88-92 \%$. It is important to continue close monitoring of both physiological, in particularly respiratory rate, as well as blood gas parameters. Patients should be monitored for level of alertness, patient ventilator synchrony, use of accessory muscles and chest wall movement. The patient's comfort level should be monitored along with mask fit, leakage and the skin in contact with mask. Arterial blood gas (ABG) measurement should generally be performed at 1,4 and 12 hours of initiation of NIV and thereafter guided by response until correction of acidosis.

\section{NIV FAILURE}

It is very important to identify when a patient is failing with NIV, and if ETI and MV are considered appropriate for that patient, to discontinue NIV and intubate the patient in a timely manner. In an analysis of the patients recruited to the YONIV trial ${ }^{24}$, the change in respiratory rate and $\mathrm{pH}$ between randomisation and four hours was a very useful indicator of outcome. If both improved, the prognosis with NIV was excellent; if both got worse, there was a high likelihood of ETI or death. If one stable and the other improved, the outcome likelihood was intermediate between the above (table 1). Confalonieri et al..$^{25}$ took this further in a larger group of patients treated in intermediate respiratory ICUs adding Glasgow coma score and acute physiology and chronic health evaluation (Apache) II score and creating a chart of likelihood of success or failure with NIV based upon baseline measures and those after 2 hours (Fig. 3).

A large study, including over 7 million patient episodes, of the outcome of a patient hospitalised because of an AECOPD in the USA between 1998 and 2008 showed that overall the survival rate improved ${ }^{26}$. There was one group however in whom the outcome was worse 


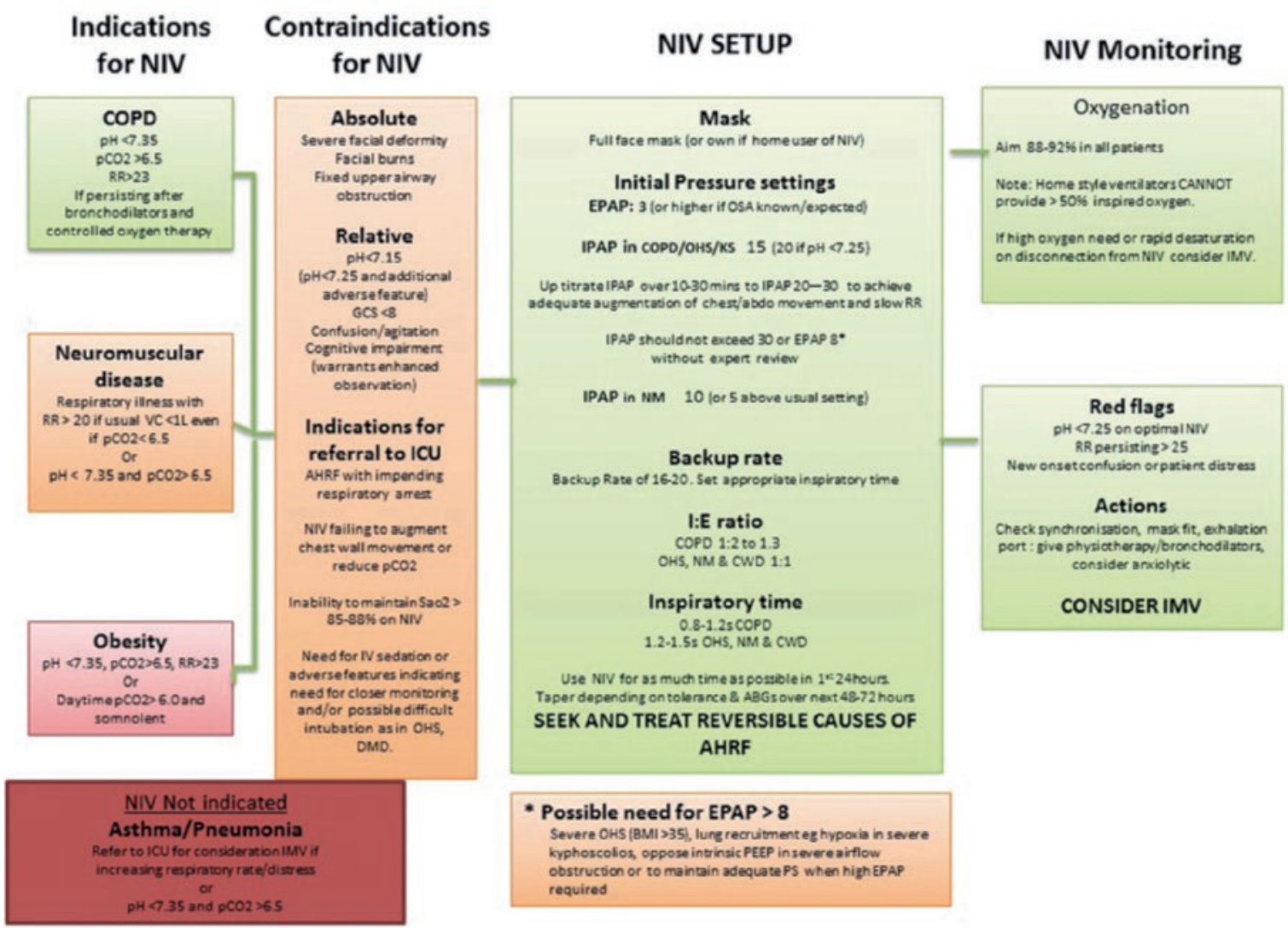

FIGURE 2. Summary of indications, contraindications, initial setup and monitoring of non invasive ventilation (NIV) (reproduced with permission. Copyright (C) 2016 BMJ Publishing Group Ltd \& British Thoracic Society. All rights reserved.).

AHRF: acute hypercapnic respiratory failure; CHD: chronic wasting disease; DMD: duchenne muscular dystrophy; COPD: chronic obstructive pulmonary disease; EGS: Glasgow coma scale; EPAP; expiratory positive airway pressure; ICU: intensive care unit; IMV: intermittent mandatory ventilation; IPAP: inspiratory positive airway pressure; KS: kyphoscoliosis; NIV: non invasive ventilation; OHS: obesity hypoventilation syndrome; $\mathrm{pCO}_{2}$ : partial pressure of carbon dioxide in arterial blood; RR: respiratory rate.

TABLE 1

\begin{tabular}{|c|c|c|c|c|c|c|}
\hline Initial pH & $\mathrm{pH}$ at $4 \mathrm{~h}$ & RR -8/min & $\mathrm{RR}-4 / \mathrm{min}$ & RR no change & $\mathrm{RR}+4 / \mathrm{min}$ & $\mathrm{RR}+8 / \mathrm{min}$ \\
\hline \multirow[t]{3}{*}{7.30} & 7.35 & 0.27 & 0.38 & 0.53 & 0.74 & 1.03 \\
\hline & 7.30 & 0.51 & 0.72 & 1.00 & 1.40 & 1.95 \\
\hline & 7.25 & 1.05 & 1.46 & 2.04 & 2.85 & 3.97 \\
\hline \multirow[t]{3}{*}{7.25} & 7.35 & 0.13 & 0.19 & 0.26 & 0.36 & 0.51 \\
\hline & 7.30 & 0.25 & 0.35 & 0.49 & 0.68 & 0.96 \\
\hline & 7.25 & 0.51 & 0.72 & 1.00 & 1.40 & 1.95 \\
\hline
\end{tabular}

A chart of predictors of failure with non-invasive ventilation in an acute exacerbation of chronic obstructive respiratory disease (COPD). Relative risk of meeting predefined criteria indicating need for endotracheal intubation based on respiratory rate and pH at initiation of non invasive ventilation (NIV) and after 4 hours. No change in either parameter ascribed relative risk of 1.0. If both improved the prognosis with NIV excellent, if both worse there was a high likelihood of endotracheal intubation (ETI) or death. If one stable and the other improved the outcome likelihood was intermediate between the above.

RR: respiratory rate. 


\begin{tabular}{|c|c|c|c|c|c|c|c|}
\hline & & \multicolumn{2}{|c|}{$\mathrm{pH}$ admission $<7.25$} & \multicolumn{2}{|c|}{$\mathrm{pH}$ admission $7.25-7.29$} & \multicolumn{2}{|c|}{$\mathrm{pH}$ admission $>7.30$} \\
\hline & RR & APACHE $\geq 29$ & APACHE $<29$ & $\mathrm{APACHE} \geq 29$ & APACHE $<29$ & $\mathrm{APACHE} \geq 29$ & APACHE $<29$ \\
\hline \multirow{3}{*}{$\begin{array}{c}\text { GCS } \\
15\end{array}$} & $<30$ & 29 & 11 & 18 & 6 & 17 & 6 \\
\hline & $30-34$ & 42 & 18 & 29 & 11 & 27 & 10 \\
\hline & $\geq 35$ & 52 & 24 & 37 & 15 & 35 & 14 \\
\hline \multirow{3}{*}{$\begin{array}{c}\text { GCS } \\
12-14\end{array}$} & $<30$ & 48 & 22 & 33 & 13 & 32 & 12 \\
\hline & $30-34$ & 63 & 34 & 48 & 22 & 46 & 21 \\
\hline & $\geq 35$ & 71 & 42 & 57 & 29 & 55 & 27 \\
\hline \multirow{3}{*}{$\begin{array}{l}\text { GCS } \\
\leq 11\end{array}$} & $<30$ & 64 & 35 & 49 & 23 & 47 & 21 \\
\hline & $30-34$ & 76 & 49 & 64 & 35 & 62 & 33 \\
\hline & $\geq 35$ & 82 & 59 & 72 & 44 & 70 & 42 \\
\hline
\end{tabular}

\begin{tabular}{|c|c|c|c|c|c|c|c|}
\hline & & \multicolumn{2}{|c|}{$\mathrm{pH}$ after $2 \mathrm{~h}<7.25$} & \multicolumn{2}{|c|}{$\mathrm{pH}$ after $2 \mathrm{~h} 7.25-7.29$} & \multicolumn{2}{|c|}{$\mathrm{pH}$ after $2 \mathrm{~h} \geq 7.30$} \\
\hline & RR & APACHE $\geq 29$ & APACHE $<29$ & APACHE $\geq 29$ & APACHE $<29$ & APACHE $\geq 29$ & APACHE $<29$ \\
\hline \multirow{3}{*}{$\underset{15}{\mathrm{GCS}}$} & $<30$ & 72 & 35 & 27 & 7 & 11 & 3 \\
\hline & $30-34$ & 88 & 59 & 49 & 17 & 25 & 7 \\
\hline & $\geq 35$ & 93 & 73 & 64 & 27 & 38 & 11 \\
\hline \multirow{3}{*}{$\begin{array}{c}\text { GCS } \\
12-14\end{array}$} & $<30$ & 84 & 51 & 41 & 13 & 19 & 5 \\
\hline & $30-34$ & 93 & 74 & 65 & 28 & 39 & 12 \\
\hline & $\geq 35$ & 96 & 84 & 78 & 42 & 54 & 20 \\
\hline \multirow{3}{*}{$\begin{array}{l}\text { GCS } \\
\leq 11\end{array}$} & $<30$ & 93 & 74 & 65 & 28 & 39 & 12 \\
\hline & $30-34$ & 97 & 88 & 83 & 51 & 63 & 26 \\
\hline & $\geq 35$ & 99 & 93 & 90 & 66 & 76 & 40 \\
\hline
\end{tabular}

$0-24 \%=25-49 \%=50-74 \%-75-100 \%$

Figure 3. A chart of predictors of failure with non invasive ventilation (NIV). Top panel at initiation. Bottom panel after 2 hours. Similar approach to table 1 but with more parameters. The values in the table correspond to the percentage of patients who fall in each category (reproduced with permission from the CERS 2005. European Respiratory Journal Feb 2005, 25 (2) 348-355; D0I: 10.1183/09031936.05.00085304). APACHE: acute physiology and chronic health evaluation; GCS: Glasgow coma scale; RR: respiratory rate.

and that was in the group who were initially treated with NIV but subsequently required ETI and MV. This was attributed to delay in intubation, but Nava and Elliott ${ }^{27}$ in an accompanying editorial suggested an alternative explanation for some patients, namely that the patient who tolerates NIV well but deteriorates may not be a good candidate for ETI and MV. An earlier case series showed a poor outcome in patients who initially improved with NIV but then deteriorated ${ }^{28}$. These patients had a high mortality whether treated with continued NIV or ETI and
IMV. Late failure was more likely in patients with low activity of daily living scores, comorbidities and very severe acidosis. Before resorting to ETI and MV, it is important to identify and correct any problems that may be contributing to the failure of NIV and to correct them - table 2 provides a useful checklist. When considering "failure of NIV" it is important to distinguish between failure of "non invasive" and of "ventilation". The former tends to be due to intolerance of the mask ad occurs early. There may still be time for medical therapy to have an effect 
TABLE 2. A checklist of technical issues for when NIV is failing

\begin{tabular}{|l|l|l|}
\hline Problem & \multicolumn{1}{|c|}{ Cause(s) } & \multicolumn{1}{c|}{ Solution(s) } \\
\hline Ventilator cycling independently of patient effort & $\begin{array}{l}\text { Inspiratory trigger sensitivity is too high } \\
\text { Excessive mask leak }\end{array}$ & $\begin{array}{l}\text { Adjust trigger } \\
\text { Reduce mask leak }\end{array}$ \\
\hline Ventilator not triggering despite visible patient effort & $\begin{array}{l}\text { Excessive mask leak } \\
\text { Inspiratory trigger sensitivity is too low }\end{array}$ & $\begin{array}{l}\text { Reduce mask leak } \\
\text { Adjust trigger } \\
\text { For NM patients consider switch to PCV }\end{array}$ \\
\hline $\begin{array}{l}\text { Inadequate chest expansion despite apparent } \\
\text { triggering }\end{array}$ & Inadequate Tidal volume & $\begin{array}{l}\text { Increase IPAP. In NM or chest wall disease } \\
\text { consider longer Ti }\end{array}$ \\
\hline $\begin{array}{l}\text { Chest/abdominal paradox } \\
\text { Premature expiratory effort by patient }\end{array}$ & Uppper airway obstruction & $\begin{array}{l}\text { Avoid neck flexion } \\
\text { Increase EAP }\end{array}$ \\
\hline
\end{tabular}

EPAP: expiratory positive airway pressure; IPAP: inspiratory positive airway pressure; NIV: non invasive ventilation; NM: neuromuscular disease; PCV: pressure-controled ventilation; Ti: inspiratory time.

and there is reason to believe that replacement of an ineffective interface with a more effective one, namely an endotracheal tube, may be beneficial. Contrast that with failure of "ventilation"; here the interface is tolerated and ventilation can be delivered effectively but despite this the patient deteriorates. This tends to occur later when medical therapy has already achieved what it can and replacement of an interface that is working well with a different one (i.e., an endotracheal tube) is unlikely to be more effective. This is likely to be the patient with advanced lung disease who is very difficult to ventilate and a more palliative approach may be more appropriate. Predicting the end of life in patients with COPD is notoriously difficult ${ }^{29}$ and patients may be near death one day and wanting to go home the next ${ }^{30}$. NIV is very useful in this situation, providing both life sustaining treatment and effective palliation of the major symptom, namely dyspnoea, in a patient with severe COPD ${ }^{31}$. The patient retains the opportunity to be involved in decisions about his care and it is easier to move to a purely palliative approach than when a patient has been intubated.

\section{VENTILATORY FAILURE DEVELOPING, OR WORSENING, AFTER ADMISSION}

The BTS audit also highlighted another important issue, namely how acidosis may evolve over the course of an admission to hospital and that this impacts upon outcome ${ }^{18}$. The prognosis was best in those for whom the $\mathrm{pH}$ was lowest on admission ( $9 \%$ inpatient mortality in those treated conventionally - group 1). The outcome was much worse when patients were acidotic on admission but a subsequent $\mathrm{pH}$ was lower $(21 \%$ inpatient mortality in those treated conventionally - group 2) nor those who initially had a normal $\mathrm{pH}$ but became acidotic during the admission ( $27 \%$ inpatient mortality in those treated conventionally - group 3). Most of the patients in the RCTs started NIV on or soon after admission and the results may not be applicable to these latter two patient groups. However, in a large study $(\mathrm{n}=342)$ from China ${ }^{32}$, patients started NIV between 24 and 48 hours after admission. The authors showed a reduction in ETI rate from $15 \%$ in the control arm to $5 \%(\mathrm{p}=0.02)$ in the NIV arm. Inflation pressures were modest (IPAP $12.9 \pm 9 \mathrm{cmH}_{2} \mathrm{O}$; EPAP $4.3 \pm 1.2 \mathrm{cmH}_{2} \mathrm{O}$ ) and $90 \%$ of patients were 
ventilated for more than 4 days (mean $10 \pm 7$ days, $11 \pm 5$ days , respectively); these figures compare very favourably with usage statistics from other studies. The high need for ETI in the control arm is surprising, given that the average $\mathrm{pH}$ at randomisation in the two groups was only borderline acidotic (7.34 versus 7.35); an advantage was seen in the non acidotic sub group in a post-hoc analysis. However, the time after admission at which NIV was initiated suggests that many of these patients may have been from the groups 2 and 3 identified in the BTS audit, i.e. those with a much worse prognosis. Recent guidelines do not recommend a change from previously in the $\mathrm{pH}$ criteria for initiating NIV, but these data do provide a rationale for the use of NIV in those who deteriorate after admission to hospital and suggest that more prolonged ventilation during the acute episode may be appropriate. More data are needed about longer term outcomes in these patients and also, given the prolonged duration of hospitalisation necessary, whether this approach is cost effective. Previous studies have shown that the longer term prognosis in patients who have had an AECOPD requiring NIV is poor ${ }^{24,25,34}$. These patients may also be frequently readmitted to hospital $21,34,35$, though this can be reduced by the provision of domiciliary NIV $^{36}$. There is a danger that patients spend their last few months of life lurching from one crisis to another with much of their time spent in hospital with life of marginal quality.

\section{SEDATION}

In intubated patients, sedation and analgesia are essential to increase tolerance of the endotracheal tube and suction procedures, to reduce anxiety, facilitate patient-ventilator interaction and help the patient to tolerate invasive procedures ${ }^{37}$. Non invasive ventilation is usually applied in spontaneously breathing patients, who can trigger the ventilator and and protect their airway. Sedation in patients undergoing NIV should aim to guarantee good control of agitation, anxiety and dyspnoea as well as improve patient-ventilator interaction and sleep. It should reduce respiratory rate and inspiratory effort while avoiding abolition of respiratory drive and preserving upper airway patency. There is little evidence to guide practice. The use of several different drugs has been described in a number of small scale studies suggesting benefit. Drugs include Morphine, Remifentanil, Propofol, Dexmetomidine and Benzodiazepines. Each has a potential role in different situations. An international, prospective, observational multicentre study evaluated the effects of sedative-analgesic therapy in NIV failure ${ }^{38}$. The study involved 322 ICUs in 30 countries, including more than 840 patients with respiratory failure of a wide range of aetiologies who had received, as initial treatment, at least two hours of NIV after admission to the ICU. Analgesia and sedation were used only in $19.6 \%$ of patients, confirming the data of a previous survey ${ }^{39}$. Analgesia or sedation did not reduce NIV failure, defined as the need for ETI. Indeed, using a rigorous statistical method, an increased risk of NIV failure and increased mortality was seen in patients who were treated with both analgesic and sedatives agents. If sedatives are used, it should be in a very well monitored environment. Further studies, particularly RCTs, are required.

\section{DURATION OF NIV}

Guidelines ${ }^{20}$ suggest that patients who respond to NIV during the first few hours should have 
as much NIV as possible during the first 24 hours. If improvement in both physiological and blood gas parameters continues, the amount of NIV usage should be gradually reduced over the next 48 hours, starting with more breaks during day time. However, in a recently published $\mathrm{RCT}^{40}$ patients with COPD who had received NIV for AHRF and tolerated unassisted breathing for 4 hours with $\mathrm{pH}>7.35$ were randomly allocated to receive three additional nights of NIV $(n=61)$ or discontinuation $(n=59)$. In the group who immediately discontinued NIV, there was a shorter median (interquartile range) intermediate respiratory care unit stay (4 (2-6) versus 5 (4-7) days, $\mathrm{p}=0.036)$, There was no difference in the primary outcome, relapse of AHRF (10 $(17 \%)$ versus $8(13 \%), p=0.56)$ or in longterm ventilator dependence, hospital stay, readmission to hospital in the subsequent 6 months or survival. This study suggests that NIV can be discontinued when the acidosis is resolved and patient can tolerate unassisted breathing for 4 hours. In an accompanying editorial it was suggested that caution be exercised in extrapolating to patients with more severe AHRF as the mean $\mathrm{pH}$ at initiation of NIV in this study was $7.29^{41}$.

\section{Other conditions causing AHRF treated with acute NIV}

There are other conditions in which patients can present with AHRF and these may be misdiagnosed as COPD. Respiratory failure should only be ascribed to COPD if the diagnosis has been confirmed, either previously or during the admission, with spirometry. Neuromuscular conditions should be considered as part of the differential diagnosis of otherwise unexplained AHRF. There are rare muscle disorders, Pompe's disease (acid maltase deficiency) and Nemaline myopathy, in which respiratory muscle involvement occurs early, before there is significant peripheral muscle weakness. Although the respiratory muscles are less commonly involved in other muscle disorders they can be ${ }^{42}$; the possibility that the respiratory muscles might be involved should be considered in every patient with a neuromuscular disorder (NMD). Symptoms are very non specific and there should be a low threshold for performing ABGs, spirometry and mouth pressures. Motor neurone disease (MND) may present with respiratory failure before a diagnosis has been made ${ }^{43}$. If suspected, a careful neurological history and examination should be performed. Muscle fasciculation should be sought, but note that high $\mathrm{PaCO}_{2}$ may cause muscular twitching. The diagnosis should be confirmed by a neurologist and neurophysiological testing.

Patients with AHRF due to NMD will usually require long term domiciliary ventilation. Hypercapnia usually indicates that the patient is in a precarious situation and it is reasonable to start NIV if patients are admitted with an acute respiratory illness and hypercapnia but without acidosis. Indeed, in patients with NMD, NIV can be started if they have a markedly reduced vital capacity and are tachypnoeic, even if normocapnic ${ }^{20}$. A high respiratory rate cannot be sustained and the patient will fatigue and the $\mathrm{CO}_{2}$ will rise. Patients with NMD with normal underlying lungs can usually be ventilated with low pressures.

Obesity hypoventilation syndrome (OHS) or extra pulmonary restrictive conditions, such as early onset kyphoscoliosis, can present with AHRF, though usually symptoms suggesting 
nocturnal hypoventilation have been present for some time. Patients with obesity have similar or better outcomes than patients with $\mathrm{COPD}^{44}$. Similar criteria to initiate NIV as for AECOPD can be used ${ }^{20}$. Patients with these conditions with chronic hypercapnia (indicated by an elevated bicarbonate and base excess) are likely to require longer term ventilatory support and it is appropriate to consider NIV, even in the absence of acidosis. In a RCT of patients with OHS, Masa et al. ${ }^{45}$ showed that NIV and CPAP were more effective than lifestyle modification in improving clinical symptoms and polysomnographic parameters over a two-month follow up period, although NIV lead to better respiratory functional improvements than did CPAP. In a recently published $\mathrm{RCT}$, Howard et al. ${ }^{46}$ showed that in patients with newly diagnosed severe $\mathrm{OHS}\left(\mathrm{PaCO}_{2}\right.$ approximately $60 \mathrm{~mm} \mathrm{Hg}$ ) NIV and CPAP resulted in similar improvements in ventilatory failure, quality of life and adherence to therapy. A high $\mathrm{PaCO}_{2}$ at baseline was the only predictor of persistence of ventilatory failure at three months. Obese patients are likely to require a high IPAP, because of the high impedance to inflation, and a high EPAP, because of coexistent upper airway obstruction, to achieve acceptable minute ventilation. For obese patients, CPAP is the modality of first choice for domiciliary treatment.

\section{THE FUTURE?}

There are likely to be future developments in interface technology and also monitoring. Modes of ventilation which in theory should provide more effective $\mathrm{NIV}^{47,48}$ have failed to establish a role for themselves in everyday practice, though there is a minor resurgence of interest in neutrally adjusted ventilatory assistance (NAVA) ${ }^{49,50}$. High flow nasal oxygen (HFNO) appears to have a role in hypoxaemic respiratory failure ${ }^{51}$; a higher $\mathrm{F}_{\mathrm{I}} \mathrm{O}_{2}$ can be delivered more consistently and comfortably but it remains to be seen whether the small physiological effects, dead space wash out and a low level of PEEP and better humidification are sufficient to have an important effect in AHRF. Its use as an adjunct to NIV, with the patient receiving HFNO during breaks, is theoretically attractive. However, HFNO must not become a form of "NIV-LIGHT" and enter routine practice without robust clinical trial data. Another area of potential interest is extra corporeal removal of carbon dioxide; that this can be achieved with low flow veno-venous access is attractive and there are reports of its use in patients in whom $\mathrm{CO}_{2}$ cannot be controlled with NIV ${ }^{52}$. Further studies, particularly evaluating what happens post event, and cost effectiveness are needed.

\section{CONCLUSIONS}

NIV is part of the main stream of acute respiratory and critical care medicine and has a well developed, and evidence-based, role in the management of AECOPD. It is also used successfully in other conditions causing AHRF and is usually the first line intervention in all but a very few cases. Other technologies may complement NIV in the future but must be evaluated for cost effectiveness and longer term consequences. As much research effort needs to be put into developing communication strategies with patients to ensure that the point at which "enough is enough" is not regularly passed, in an effort to prolong life at all costs ${ }^{53}$. 


\section{CONFLICTS OF INTEREST}

Dr. Elliott reports personal fees from PhilipsRespironics, personal fees from Agir a Dom, personal fees from ResMed, personal fees from Curative medical, outside the submitted work.

\section{REFERENCES}

1. From the Global Strategy for the Diagnosis, Management and Prevention of COPD, Global Initiative for Chronic Obstructive Lung Disease (GOLD) 2017. Available from: http://goldcopd.org.

2. Lightowler JV, Wedzicha JA, Elliott MW, Ram FS. Non-invasive positive pressure ventilation to treat respiratory failure resulting from exacerbations of chronic obstructive pulmonary disease: Cochrane systematic review and meta-analysis. BMJ.2003;326:185.

3. Keenan SP, Massel D, Inman KJ, Sibbald WJ. A systematic review of the cost-effectiveness of noncardiac transitional care units. Chest. 1998; 113:172-7.

4. Plant PK, Owen JL, Parrott S, Elliott MW. Cost effectiveness of ward based non-invasive ventilation for acute exacerbations of chronic obstructive pulmonary disease: economic analysis of randomised controlled trial. British Medical Journal. 2003;326:956-61.

5. Sadoul P, Aug M, Gay R. Traitement par ventilation instrumentale de 100 cas d'insuffisants respiratoires chroniques. Bull Eur Physiopathol Respir. 1965;1:519-49

6. Macklem PT. Hyperinflation. Am Rev Respir Dis. 1984;129:1-2.

7. Gorini M, Spinelli A, Ginanni R, Duranti R, Gigliotti F, Scano G. Neural respiratory drive and neuromuscular coupling in patients with chronic obstructive pulmonary disease (COPD). Chest. 1990;98:1179-86.

8. Petrof BJ, Legare M, Goldberg P, Milic-Emili J, Gottfried SB. Continuous positive airway pressure reduces work of breathing and dyspnea during weaning from mechanical ventilation in severe chronic obstructive pulmonary disease. Am Rev Respir Dis. 1990;141:281-9.

9. Brochard L, Mancebo J, Wysocki M et al. Noninvasive ventilation for acute exacerbations of chronic obstructive pulmonary disease. N Engl J Med. 1995;333:817-22.

10. Kramer N, Meyer TJ, Meharg J, Cece RD, Hill NS. Randomized, prospective trial of noninvasive positive pressure ventilation in acute respiratory failure. Am J Respir Crit Care Med. 1995;151:1799-806.

11. Elliott MW, Steven MH, Phillips GD, Branthwaite MA. Non-invasive mechanical ventilation for acute respiratory failure. BMJ. 1990;300:358-60.

12. Bott J, Carroll MP, Conway JH et al. Randomised controlled trial of nasal ventilation in acute ventilatory failure due to chronic obstructive airways disease. Lancet. 1993;341:1555-7.

13. Girou E, Schortgen F, Delclaux C et al. Association of noninvasive ventilation with nosocomial infections and survival in critically ill patients. JAMA. 2000;284:2361-7.

14. Girou E, Brun-Buisson C, Taille S, Lemaire F, Brochard L. Secular trends in nosocomial infections and mortality associated with noninvasive ventilation in patients with exacerbation of COPD and pulmonary edema. JAMA. 2003;290:2985-91.

15. Plant PK, Owen JL, Elliott MW. Early use of non-invasive ventilation for acute exacerbations of chronic obstructive pulmonary disease on general respiratory wards: a multicentre randomised controlled trial. Lancet. 2000; 355:1931-5
16. Carlucci A, Delmastro M, Rubini F, Fracchia C, Nava S. Changes in the practice of non-invasive ventilation in treating COPD patients over 8 years. Intensive Care Med. 2003;29:419-25.

17. Plant PK, Owen JL, Elliott MW. One year period prevalence study of respiratory acidosis in acute exacerbations of COPD: implications for the provision of non-invasive ventilation and oxygen administration. Thorax. 2000; 55:550-4.

18. Roberts CM, Stone RA, Buckingham RJ, Pursey NA, Lowe D. Acidosis, non-invasive ventilation and mortality in hospitalised COPD exacerbations. Thorax. 2011;66:43-8.

19. Austin MA, Wills KE, Blizzard L, Walters EH, Wood-Baker R. Effect of high flow oxygen on mortality in chronic obstructive pulmonary disease patients in prehospital setting: randomised controlled trial. BMJ. 2010; 341:c5462.

20. Davidson AC, Banham S, Elliott M et al. BTS/ICS guideline for the ventilatory management of acute hypercapnic respiratory failure in adults. Thorax. 2016;71 Suppl 2:ii1-35.

21. Conti G, Antonelli M, Navalesi P et al. Noninvasive vs. conventional mechanical ventilation in patients with chronic obstructive pulmonary disease after failure of medical treatment in the ward: a randomized trial. Intensive Care Med. 2002;28:1701-7.

22. Jurjevic M, Matic I, Sakic-Zdravcevic K, Sakic S, Danic D, Bukovic D. Mechanical ventilation in chronic obstructive pulmonary disease patients, noninvasive vs. invasive method (randomized prospective study). Coll Antropol. 2009;33:791-7.

23. Diaz GG, Alcaraz AC, Talavera JCP et al. Noninvasive Positive-Pressure Ventilation To Treat Hypercapnic Coma Secondary to Respiratory Failure. Chest. 2005;127:952-60.

24. Plant PK, Owen JL, Elliott MW. Non-invasive ventilation in acute exacerbations of chronic obstructive pulmonary disease: long term survival and predictors of in-hospital outcome. Thorax. 2001;56:708-12.

25. Confalonieri M, Garuti G, Cattaruzza MS et al. A chart of failure risk for noninvasive ventilation in patients with COPD exacerbation. Eur Respir J. 2005;25:348-55

26. Chandra D, Stamm JA, Taylor B et al. Outcomes of noninvasive ventilation for acute exacerbations of chronic obstructive pulmonary disease in the United States, 1998-2008. Am J Respir Crit Care Med. 2012;185:152-9.

27. Elliott MW, Nava S. Noninvasive ventilation for acute exacerbations of chronic obstructive pulmonary disease: "Don't think twice, it's alright!". Am J Respir Crit Care Med. 2012;185:121-3.

28. Moretti M, Cilione C, Tampieri A, Fracchia C, Marchioni A, Nava S. Incidence and causes of non-invasive mechanical ventilation failure after initial success. Thorax. 2000;55:819-25.

29. A controlled trial to improve care for seriously ill hospitalized patients. The study to understand prognoses and preferences for outcomes and risks of treatments (SUPPORT). The SUPPORT Principal Investigators. JAMA. 1995;274:1591-8.

30. Lanken PN, Terry PB, Delisser HM et al. An official American Thoracic Society clinical policy statement: palliative care for patients with respiratory diseases and critical illnesses. Am J Respir Crit Care Med. 2008; 177:912-27.

31. Nava S, Ferrer M, Esquinas A et al. Palliative use of non-invasive ventilation in end-of-life patients with solid tumours: a randomised feasibility trial. Lancet Oncol. 2013;14:219-27.

32. Collaborative Research Group of Noninvasive Mechanical Ventilation for Chronic Obstructive Pulmonary Disease (CRGONMVFCOP). [Early use of noninvasive positive pressure ventilation for patients with acute exacerbations of chronic obstructive pulmonary disease: a multicentre randomized controlled trial]. Chinese Medical Journal. 2005;28:680-4.

33. Confalonieri M, Parigi P, Scartabellati A et al. Noninvasive mechanical ventilation improves the immediate and long-term outcome of COPD patients with acute respiratory failure. Eur Respir J. 1996;9:422-30.

34. Chu CM, Chan VL, Lin AWN, Wong IWY, Leung WS, Lai CKW. Readmission rates and life threatening events in COPD survivors treated with non-invasive ventilation for acute hypercapnic respiratory failure. Thorax. 2004;59:1020-5. 
35. Connors AF, Jr., Dawson NV, Thomas C et al. Outcomes following acute exacerbation of severe chronic obstructive lung disease. The SUPPORT investigators (Study to Understand Prognoses and Preferences for Outcomes and Risks of Treatments). Am J Respir Crit Care Med. 1996;154:959-67.

36. Murphy PB, Rehal S, Arbane G et al. Effect of Home Noninvasive Ventilation With Oxygen Therapy vs Oxygen Therapy Alone on Hospital Readmission or Death After an Acute COPD Exacerbation: A Randomized Clinical Trial. JAMA. 2017;317:2177-86.

37. Barr J, Fraser GL, Puntillo K et al. Clinical practice guidelines for the management of pain, agitation, and delirium in adult patients in the intensive care unit. Crit Care Med. 2013;41:263-306.

38. Muriel A, Penuelas O, Frutos-Vivar F et al. Impact of sedation and analgesia during noninvasive positive pressure ventilation on outcome: a marginal structural model causal analysis. Intensive Care Med. 2015;41:1586-600.

39. Devlin JW, Nava S, Fong JJ, Bahhady I, Hill NS. Survey of sedation practices during noninvasive positive-pressure ventilation to treat acute respiratory failure. Crit Care Med. 2007;35:2298-302.

40. Sellares J, Ferrer M, Anton A et al. Discontinuing noninvasive ventilation in severe chronic obstructive pulmonary disease exacerbations: a randomised controlled trial. Eur Respir J. 2017 Jul 5;50(1).

41. Nava S, Ergan B. I want to break free: liberation from noninvasive ventilation. Eur Respir J. 2017 Jul 5;50(1).

42. Shahrizaila N, Kinnear WJ, Wills AJ. Respiratory involvement in inherited primary muscle conditions. J Neurol Neurosurg Psychiatry. 2006;77:1108-15.

43. Bradley MD, Orrell RW, Clarke J et al. Outcome of ventilatory support for acute respiratory failure in motor neurone disease. J Neurology Neurosurg Psychiatry. 2002;72:752-6.
44. Carrillo A, Ferrer M, Gonzalez-Diaz G et al. Noninvasive ventilation in acute hypercapnic respiratory failure caused by obesity hypoventilation syndrome and chronic obstructive pulmonary disease. Am J Respir Crit Care Med. 2012;186:1279-85.

45. Masa JF, Corral J, Alonso ML et al. Efficacy of Different Treatment Alternatives for Obesity Hypoventilation Syndrome. Pickwick Study. Am J Respir Crit Care Med. 2015;192:86-95.

46. Howard ME, Piper AJ, Stevens B et al. A randomised controlled trial of CPAP versus non-invasive ventilation for initial treatment of obesity hypoventilation syndrome. Thorax. 2017;72:437-44.

47. Navalesi P, Hernandez P, Wongsa A, Laporta D, Goldberg P, Gottfried SB Proportional assist ventilation in acute respiratory failure: effects on breathing pattern and inspiratory effort. Am J Respir Crit Care Med. 1996;154:1330-8

48. Sinderby C, Navalesi P, Beck J et al. Neural control of mechanical ventilation in respiratory failure. Nat Med. 1999;5:1433-6.

49. Demoule A, Clavel M, Rolland-Debord C et al. Neurally adjusted ventilatory assist as an alternative to pressure support ventilation in adults: a French multicentre randomized trial. Intensive Care Med. 2016;42:1723-32.

50. Kuo NY, Tu ML, Hung TY et al. A randomized clinical trial of neurally adjusted ventilatory assist versus conventional weaning mode in patients with COPD and prolonged mechanical ventilation. Int J Chron Obstruct Pulmon Dis. 2016;11:945-51.

51. Frat JP, Thille AW, Mercat A et al. High-flow oxygen through nasal cannula in acute hypoxemic respiratory failure. N Engl J Med. 2015;372:2185-96.

52. Nava S, Ranieri VM. Extracorporeal lung support for COPD reaches a crossroad. Lancet Respir Med. 2014;2:350-2.

53. Bradley N. Kieran Sweeney. BMJ. 2010;340. 